\title{
AN APPLICATION OF TRAMO-SEATS: MODEL SELECTION AND OUT-OF-SAMPLE PERFORMANCE. THE SWISS CPI SERIES
}

Agustín Maravall and Fernando J. Sánchez

Banco de España - Servicio de Estudios

Documento de Trabajo n. ${ }^{\circ} 0014$ 


\section{An Application of TRAMO-SEATS: Model Selection and Out-of-sample Performance.}

\section{The Swiss CPI series.}

Agustín Maravall and Fernando J. Sánchez ${ }^{1}$

Información y Métodos de Cálculo; Servicio de Estudios - Banco de España; Alcalá 50; 28014 Madrid; Email: maravall@bde.es; fjsanchez@bde.es.

Thanks are due to Nicolas Fasel and Monique Graf for their valuable help. 


\begin{abstract}
This paper applies the programs TRAMO ("Time Series Regression with ARIMA Noise, Missing Observations and Outliers " ) and SEATS (" Signal Extraction in ARIMA Time Series" ) to seasonal adjustment of the monthly Consumer Price Index Swiss series. It is shown how the results of the purely automatic procedure can be improved with two simple modifications: one that emerges from the TRAMO-SEATS diagnostics, and another that uses "a-priori" information. In particular, the SEATS output is used to select a model among the ones that are equally compatible with the sample. Identification and estimation is done for data finishing in May 1999, and 10 additional observations are used to illustrate the out-of-sample performance of the TRAMO-SEATS procedure.
\end{abstract}

Keywords: Time series, ARIMA models, Seasonal adjustment, Trend estimation, Outliers.

JEL classification: C22, C49, C5, C82, C87, E39. 


\section{Introduction}

The programs TRAMO, "Time Series Regression with ARIMA Noise, Missing Observations and Outliers", and SEATS, "Signal Extraction in ARIMA Time Series", Gomez and Maravall (1996), have experienced an explosion in their use by data producing gencies and short-term economic analysts. TRAMO is a program for estimation and forecasting of regression models with possibly nonstationary ARIMA errors and any sequence of missing values. The program interpolates these values, identifies and corrects for several types of outliers, and estimates special effects such as Trading Day and Easter and, in general, intervention-variable type effects. Fully automatic procedures are available. SEATS is a program for estimation of unobserved components in time series following the so-called ARIMA-model-based (AMB) method. The trend-cycle, seasonal, irregular and perhaps transitory components are estimated and forecasted with signal extraction techniques applied to ARIMA models. The two programs are structured so as to be used together both for in-depth analysis of a few series or for automatic routine applications to a large number of series. When used for seasonal adjustment, TRAMO preadjusts the series to be adjusted by SEATS. The two programs are officially used ( and recommended) by Eurostat and, together with X12 ARIMA ( see Findley et al, 1994), by the European Central Bank.

The AMB methodology for seasonal adjustement developed from the work of Cleveland and Tiao (1976), Burman (1980), Hillmer and Tiao (1982), Bell and Hillmer (1984) and Maravall and Pierce (1987). A more complete description of the methodology behind TRAMO and SEATS can be found in Gómez and Maravall $(1994,1996,2000 a, 2000 b)$ and Maravall (1995). In essence, given the vector of observations

$$
\mathrm{y}=\left(\mathrm{y}_{\mathrm{t} 1}, \ldots, \mathrm{y}_{\mathrm{tm}}\right) \quad \text { where } 0<\mathrm{t} 1<\ldots<\mathrm{tm},
$$

TRAMO fits the regression model

$$
y_{t}=z_{t}^{\prime} \beta+x_{t}
$$

where $\beta$ is a vector of regression coefficients, $z_{t}^{\prime}$ denotes a matrix of regression variables, and $x_{t}$ follows the stochastic general ARIMA process

$$
\phi(B) \delta(B) x_{t}=\theta(B) a_{t}
$$


where $B$ is the backshift operator, $a_{t}$ is assumed a n.i.i.d. $(0, V a)$ white-noise innovation, and $\phi(B), \delta(B), \theta(B)$ are finite polynomials in $B$ that have the multiplicative form:

$\delta(B)=(1-B)^{d}\left(1-B^{s}\right)^{D}$

$\phi(B)=\left(1+\phi_{1} B+\ldots+\phi P B^{P}\right)\left(1+\Phi_{1} B^{s}\right) ;$

$\theta(B)=\left(1+\theta_{1} B+\ldots+\theta_{q} B^{q}\right)\left(1+\Theta_{1} B^{s}\right)$,

where $s$ denotes the number of observations per year. SEATS decomposes $x_{t}$ as in

$x_{t}=p_{t}+s_{t}+c_{t}+u_{t}$,

where $\mathrm{p}_{\mathrm{t}}, \mathrm{s}_{\mathrm{t}}, \mathrm{c}_{\mathrm{t}}, \mathrm{u}_{\mathrm{t}}$, are the trend-cycle, seasonal, transitory, and irregular components, which also follow ARIMA-type models, possibly with deterministic effects added. Seasonal Adjustment denotes the particular case in which

$x_{t}=n_{t}+s_{t}$

with $n_{t}=p_{t}+c_{t}+u_{t}$ representing the seasonally adjusted ( $S A$ ) series.

This paper illustrates application of the programs to the monthly CPI Swiss series for the period December 1982 - May 1999 (198 observations), displayed in Figure 0 . It is shown how the results of the purely automatic procedure ( $R S A=3$ ) can be improved with two simple modifications, one that emerges from the TRAMO-SEATS diagnostics, and another that uses a priori information. In the discusion, we shall describe some relevant considerations in the comparison of different models. and justify in this way the final choice.

One point should be stressed. If seasonal adjustment is to be carried every month, the way to proceed is not to perform a new identification every month, but to follow the procedure described in Gomez and Maravall (1998). In essence, the procedure implies the following:

a) Once-a-year reidentification of the model.

b) For the rest of the year: Fix the model orders (p,d,q,bp,bd,bq), the location and type of outliers, and the intervention variables ( when appropiate ); then, re-estimate monthly the associated parameters. 


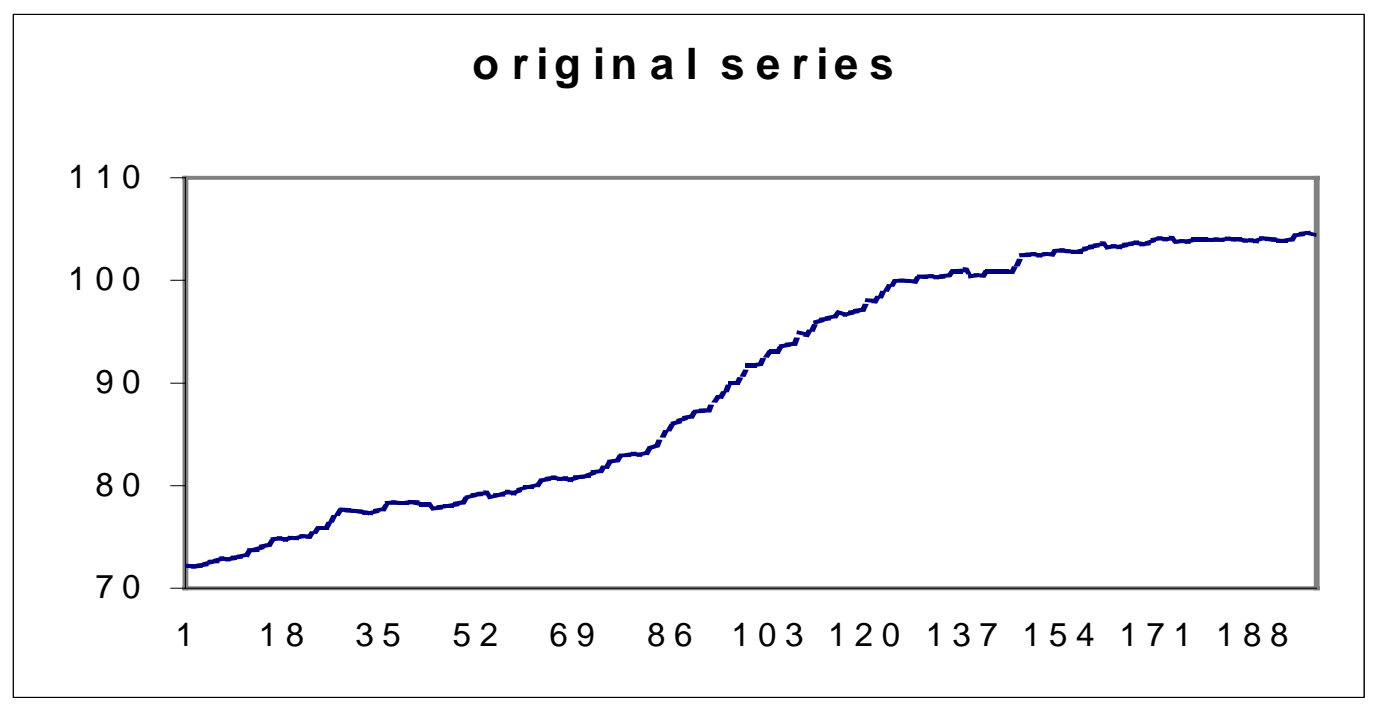

Figure 0

We looked first at identification of a suitable model ( sections 2-4) and sent the results to the Swiss Federal Statistical Office. We were then provided with 10 additional months, which we used to check the out-of-sample performance of the procedure and for a new reidentification of the model after all new months have been added ( section 5 ).

\section{Model choice and series decomposition}

\section{Model 1}

Due to the fact that we are considering a CPI series which has no trading day, easter or holiday effect, the full automatic procedure is to set simply the parameter " RSA = 3 ". ( All parameters used in this paper are described in Gomez and Maravall, 1996 ).

With the purely automatic procedure, the model $(1,1,0)(0,1,1)_{12}$ for the levels detailed in Table 1 is obtained. (All tables mentioned in Section 2 are grouped in Section 3.) It is very parsimonious and provides a good fit, and hence it should perform well in forecasting. The model contains 6 outliers, a relatively high number ( thought not unreasonable ); all outliers are concentrated in a short period ( 19901992 ), towards the middle of the series. From the first column of Table 2, the diagnostics are acceptable, except for the Normality test $(\mathrm{N})$. In particular, $\mathrm{N}=12.7$ $>$ critical level $=6$, and looking at the skewness and kurtosis, the nonnormality 
is seen to be associated mostly with the latter (therefore the effect on point forecasts will be small). The series clean of outliers (i.e., the "linearized" series) is displayed in Figure 1a (all figures mentioned in Section 2 are grouped in Section 4.)

But when decomposing the model in SEATS, the AR root $(1-.438 \mathrm{~B})$ is assigned by default to an additional "transitory component" ( because .438< $\mathrm{RMOD}=.5$ by default ) and the model does not accept then an admissible decomposition into 4 components.

SEATS automatically transforms the above ( small modulus ) AR root into an MA root, changes the model thus to a $(0,1,1)(0,1,1)_{12}$ model, reestimates the parameters and decomposes the series. Figure $2 a$ presents the residuals and they seem to display a moving mean level, which is an indication of possible nonstationarity. Looking at TRAMO for this last model, it is seen that the autocorrelation function (ACF) of the residuals has significant autocorrelation $(\mathrm{Q}(24)=55)$ and, as seen in Figure $3 \mathrm{a}$, the first 23 autocorrelations are $>0$, except for the small negative value of $\rho(12)$ ( induced by the estimation of the seasonal IMA factor). This may well be interpreted as an additional indication of nonstationarity. As before, the model residuals show high kurtosis.

SEATS decomposes the series using the approximated model. A summary of the results is contained in the first column of Table 3 . The component innovation variances show a highly stochastic trend, a considerably moving seasonal, and a heteroscedastic (small) irregular component. The trend, seasonal and irregular components are displayed in figures $4 \mathrm{a}, 5 \mathrm{a}$ and $6 \mathrm{a}$ ( because the series is strongly dominated by the trend-cycle component, the smoothing achieved by the latter is better seen by looking at the rates of growth.) The stochasticity of the seasonal component produces a not very precise estimation of seasonality. As seen in Table 3 , for historical estimation, seasonality is clearly significant; for the last year, it is borderline significant; and for the one-year ahead forecasts seasonality is not worth forecasting.

Altogether, one would like to obtain more stable, better behaved components, that can be estimated and forecast with more precission. 


\section{Model 2}

Without considering any additional information, from the TRAMO results we have seen that the residuals give some indications of possible nonstationarity. Besides, Figure 4a showed a nonconstant mean for the series rate of growth. This would point towards an increase in the regular difference to $d=2$ and, in order to protect against possible overdifferencing, to increase $q$ to 2 . Proceeding in this way, Model 2 in Table 1 is obtained. The second column of Table 2 shows that, from a fitting point of view, the results are improved. In TRAMO, nonnormality disappears, only 3 outliers, are automatically detected, and the diagnostics are passed with no problem. Figure $1 b, 2 b$ and $3 b$ show that, compared to Model 1 , the outlier correction is smaller, the mean of the residuals has lost its locally moving character, and the ACF is clean, with alternating signs.

The model is decomposable, and SEATS provides more stable components, smaller estimation errors, and seasonality is captured with more precission. The results are summarized in the second column of Table 3.

The decrease in the variance of the trend and seasonal innovations imply more stable components. Both the trend and SA series are estimated with smaller error, and subject to smaller revisions. Seasonality now is highly significant also for preliminary estimators and for the next year of forecasts. For both models, convergence of the SA series to its final estimator is relatively slow (it requires about 6 years of revisions), and there is little gain from using concurrent instead of once-a-year adjustment. The slow convergence, however, is a minor problem, since the standard desviation (SD) of the full revision in the concurrent estimator of the SA series is equal to .07 percent points, and hence of small importance. Figures $4 b, 5 b$ and $6 b$ evidence a slightly smoother trend, a more stable seasonal, and a slightly larger irregular component.

\section{$\underline{\text { Model } 3}$}

Some a-priori information, however, is available. Namely, that:

a) in May 1993 the actual weights were introduced;

b) in January 1995 there was an increase in the VAT rate;

c) in January 1999 there was another increase in the tax rate.

Therefore we tested for these possible effects by introducing them as regression variables. Several possible models were used, starting with the fully 
automatic one, with different specifications for the regression-variable effect. It became obvious that the VAT increase in January 1999 and the 1993 weights setting had insignificant effects. This was always the case for the different specifications.

As for the January 1995 effect, it was significant as a level shift (t always larger than 2). Given that, on occasion, the effect of legislative issues takes more than one month to be fully captured, we tried the specification:

\$INPUT RSA=3, IREG $=1$ \$

\$ REG ISEQ $=1, \mathrm{DELTA}=1, \mathrm{REGEFF}=1$ \$

1462

that allowed the new level to be reached in 2 months. The model obtained with the automatic procedure and the 2-month VAT specification will be referred to as Model 3 , and a summary of the model is contained in Table 1 . The model obtained is a $(0,2,1)(0,1,1)_{12}$ process, with 3 outliers and a fairly significant level shift effect associated with the January 1995 VAT change. This effect takes two months to be completed.

It should be stressed that the orders of differencing and the outliers are identical to those obtained with Model 2. The linearized series ( Figure 1c) incorporates now the removal of the VAT increase effect. The residuals ( Figure 2c ) are centered around zero and homocedastic, although they still display a moderate amount of kurtosis. As mentioned before, this feature is of little importance, given the fact that it has practically no effect on point estimation, the main effect being that the SE of the estimators provided by SEATS are to be seen as averages of (moderately) time-varying ones. For the rest, as seen in column 3 of Table 2, the TRAMO diagnostics are passed comfortably, and the BIC criterion is slightly better than the ones for models 1 and 2. In fact, the residual ACF ( Figure $3 \mathrm{c}$ ) is now clean, and the sequence of positive values has disappeared. Altogher, the results are quite good.

On the other hand, SEATS decomposes the model (third column of Table 3), and yields a trend-cycle component more stable than that of model 1 or 2 , a more stable seasonal component, and a larger irregular. The estimation errors of the trend-cycle and seasonally adjusted (SA) series are smaller. Seasonality is detected well for the last two years of the sample and for the one-year ahead forecasts, and the SEATS diagnostics are all passed. As seen in Figures 4c, 5c and $6 \mathrm{c}$, the trend-cycle of Model 3 is smoother, the seasonal component is markedly more stable, and the irregular component larger and homoscedastic. If models 1, 2 and 3 are compared, it is clear than Model 1 should be discarded. The approximation it requires provides worse fitting and worse decomposition than the other two. As for models 2 and 3 , the latter outperforms the former on practically all accounts. 


\section{Model 4}

We considered a further modification. Because the residuals of Model 3 displayed some non-normality, the critical value for outlier detection was lowered, and (as mentioned before) to protect against overdifferencing, we set $q=2$. Thus the input namelist used was:

\$INPUT LAM=1, IMEAN=0, $D=2, Q=2, I A T I P=1, V A=3.2, S E A T S=2, I R E G=1 \$$ \$REG ISEQ=1, DELTA=1, REGEFF=1 \$ 1462

and the resulting model ( Model 4 ) is detailed in Table 1.

A summary of the results is presented in the fourth column of tables 2 and 3 . In this case, the model contains 6 outliers, the 3 main ones identical to those of models 2 and 3 , and the 5 main ones identical to those of Model 1 . As seen in Figure 1d, despite the larger number of outliers, the linearized series is very similar to that produced by Model 3. The diagnostics in TRAMO are excellent, somewhat better than the ones for the previous three models, although the residuals still display some kurtosis. But the decomposition achieved by SEATS is less apealing than the one obtained with Model 3: the trend-cycle and seasonal components are less stable, the precission of the component estimators is smaller, and the revisions are larger. Figures $4 d, 5 d$ and $6 d$ display the components obtained with Model 4. Figure 7 compares the spectra of the trend and seasonal components for models 3 and 4 : the increase in stability is clearly discernible. The squared gains of the SA series and trend estimation filters, for the four models, are shown in Figure 8. For Model 3, the trend filter captures far less variation after the second harmonic. Models 2 and 3 display well-behaved and similar ( for all frequencies ) SA-series filters. Moreover, Model 4 is cleary less parsimonious than Model 3 (it has 3 more outliers and one more MA parameter), and parsimony is an important feature for model stability and out-of-sample forecasting.

Thus the best choise seems to be Model 3, that is:

a) the automatic procedure,

b) with a level shift capturing the effect of the January 1995 VAT change ( the new level reached in 2 months ). 
Figure 9 and 10 present the Wiener-Kolmogorov filters and the estimated components for the chosen decomposition. The small size of the filter weights for the SA series and trend-cycle, as well as their persistance for large lags, is in agreement with the results in Table 3 from SEATS: the revision is small, but the concurrent estimator takes a long time to converge to the historical one. Figure 11 exhibits the 2-year ahead forecast function of the series, the trend-cycle, and the seasonal component, together with the $90 \%$ probability intervals. Although the trend-cycle strongly dominates the evolution of the level, the small seasonal component can be captured with considerable precision.

As mentioned at the beginning, this procedure would be used the first month. Then, for the next months, the model orders $\left(\begin{array}{lllll}0 & 2 & 1\end{array}\right)\left(\begin{array}{lll}0 & 1 & 1\end{array}\right)_{12}$ should be maintained, as well as the 3 outliers, and the VAT-effect regression variable. The parameter IATIP should be equal to 1 , in order to detect possible new outliers during the year, and all parameters should be reestimated. After 1 year, the model could be reidentified.

The choice implies that we are willing to pay the price of some excess kurtosis in order to substantially increase parsimony and the stability of the trendcycle and seasonal components. To help in the removal of kurtosis, we considered a slightly different alternative specification for the VAT-effect regression variables. Given that, in computing the CPI series, not all prices are collected every month, perhaps a period of only 2 months is not enough to capture well the full effect of the VAT increase. We extended this period to 3 months in Model 3; in terms of the input namelist the only change is to replace the last line " 1462 " by " 1463 ", and we shall refer to this specification as Model 3'. The Normality statistics decreased in fact from 9.0 to 6.5. The price paid however was a slight deterioration of the BIC criterion and of the residual SE. The results of SEATS were practically identical to those of Model 3. The residuals, the SA series and the seasonal component for the two models are, in practice, very close. Considering that, for Model 4, when the initial period for the completion of the VAT increase effect is extended to 3 months, the results clearly deteriorate, our best option still remains model 3 , although model $3^{\prime}$ ' would also seem perfectly acceptable.

The following remark may be of interest. The VAT effect is modelled as a level shift, and if we look at the t-values of the coefficient of the associated regression variable, they are 4.2 , for model 3 and 4.2 for model 4 . Because the value used for VA ( the threshold level for the detection of outliers) is the default one, which for the present series lenght is 3.5, it is somewhat surprising that the level shift is not captured in the automatic outlier detection procedure. The reason is that, in the level shifts considered in the latter, the full impact is captured instantly ( i.e. in one month ), while we have spread it over a 2-month period. In fact, in all the cases we have considered, the t-values of the VAT regression variable is smaller than 3.5 when the period for the full level shift is left at one month. It is a 
case, thus, in which a small change in the model, justified by a priori considerations, has relatively important effects and improves results.

Model 3 implies models for the SA series $\left(n_{t}\right)$ and the seasonal component of the type

$\nabla^{3} \mathrm{n}_{\mathrm{t}}=\left(1-1.815 \mathrm{~B}+.821 \mathrm{~B}^{2}\right) \mathrm{a}_{\mathrm{nt}} ;$

$\mathrm{Ss}_{\mathrm{t}}=\theta_{\mathrm{s}}(\mathrm{B}) \mathrm{a}_{\mathrm{st}}$

where $S=1+B+\ldots+B^{11}$ and $\theta_{s}(B)$ is of order 11 . The variables $a_{n t}$ and $a_{s t}$ are orthogonal component innovations. The I(3) nature of the trend model may seem high but, if the MA polynomial is factorized, one of the roots is equal to (1- .99B), and hence indistinguishable from $\nabla$. Therefore, in practice, the model simplifies into

$\nabla^{2} \mathrm{n}_{\mathrm{t}}=(1-.834 \mathrm{~B}) \mathrm{a}_{\mathrm{nt}}+\eta$,

a sensible I(2) specification. In fact, considering that .834 is not very far from 1 , the SA series will be relatively close to the I(1) model

$\nabla n_{t}=a_{n t}+\eta_{0}+\eta_{1} t$

a random-walk plus linear-trend drift model. The example illustrates how the order of integration often is, to a large extent, an arbitrary choice. 


\section{The decomposition in tables}

\section{TABLE 1: SPECIFICATION OF THE MODELS.}

The t-values of the parameter estimates are given in parenthesis below the corresponding parameter.

\section{a) MODEL 1}

Input namelist

\$ INPUT RSA=3 \$

Model

$y_{t}=6$ outliers $+x_{t}$

$(1-.438 \mathrm{~B}) \nabla \nabla_{12} \mathrm{x}_{\mathrm{t}}=\left(1-.719 \mathrm{~B}^{12}\right) \mathrm{a}_{\mathrm{t}}$

The model does not accept an admissible decomposition and is replaced by $\nabla \nabla_{12} \mathrm{x}_{\mathrm{t}}=(1+.343 \mathrm{~B})\left(1-.688 \mathrm{~B}^{12}\right) \mathrm{a}_{\mathrm{t}}$.

(5.07) (-12.35)

\section{b) MODEL 2}

\section{Input namelist}

\$ INPUT LAM=1, IMEAN=0, D=2, Q=2, IATIP=1, SEATS=2 \$

\section{Model}

$y_{t}=3$ outliers $+x_{t}$

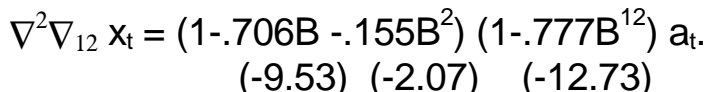

$(-9.53)(-2.07) \quad(-12.73)$ 


\section{c) MODEL 3}

\section{Input namelist}

\$ INPUT RSA $=3$, IREG $=1$ \$

\$ REG ISEQ=1, REGEFF=1, DELTA=1 \$

1462

\section{Model}

$$
\begin{aligned}
& \mathrm{y}_{\mathrm{t}}=3 \text { outliers }+\underset{(4.2)}{0.541 \mathrm{REG}+\mathrm{x}_{\mathrm{t}}} \\
& \nabla^{2} \nabla_{12} \mathrm{x}_{\mathrm{t}}=\underset{(1-.834 \mathrm{~B})\left(1-.771 \mathrm{~B}^{12}\right) \mathrm{a}_{\mathrm{t}}}{(-18.22)}(-12.35) \\
& \text { d) MODEL } 4
\end{aligned}
$$

\section{d) MODEL 4}

\section{Input namelist}

\$ INPUT LAM=1, IMEAN=0, D=2, Q=2, IREG=1, IATIP=1, VA=3.2, SEATS=2 \$ \$ REG ISEQ $=1$, REGEFF=1, DELTA=1 \$ 1462

\section{Model}

$$
\begin{aligned}
& y_{t}=6 \text { outliers }+\underset{(4.2)}{0.571 \text { REG }+x_{t}} \\
& \nabla^{2} \nabla_{12} x_{t}=\underset{\left(1-.677 B-.150 B^{2}\right)\left(1-.736 B^{12}\right)}{(-8.93)(-1.97) \quad(-11.71)} a_{t} .
\end{aligned}
$$




\section{OUTLIERS}

$\begin{array}{llllllll}\text { Date } & \mathbf{5 / 9 0} & \mathbf{1 2 / 9 0} & \mathbf{2 / 9 1} & \mathbf{5 / 9 1} & \mathbf{1 1 / 9 1} & \mathbf{1 1 / 9 2} & \mathbf{5 / 9 4} \\ & & & & & & & \\ \text { Model 1 } & \text { LS (-3.3) } & \text { TC (-3.4) } & \text { AO (3.0) } & \text { LS (4.7) } & \text { AO (6.4) } & \text { AO (5.1) } & - \\ \text { Model 2 } & - & - & - & \text { LS (3.8) } & \text { AO (5.2) } & \text { AO (4.1) } & - \\ \text { Model 3 } & - & - & - & \text { LS (3.9) } & \text { AO (4.9) } & \text { AO (3.9) } & - \\ \text { Model 4 } & - & \text { TC (-3.2) } & \text { AO (3.2) } & \text { LS (3.9) } & \text { AO (6.2) } & \text { AO (5.0) } & \text { TC (-3.1) } \\ \text { t-values are in parenthesis } & & & & & \end{array}$

\section{TABLE 2: SUMMARY STATISTICS; TRAMO}

$\begin{array}{lllll}\text { Model } & \mathbf{1} & \mathbf{2} & \mathbf{3} & \mathbf{4} \\ & & & & \\ \text { 1.S.E of residuals } & .193 & .202 & .195 & .182 \\ \text { 2.BIC } & -3.11 & -3.06 & -3.14 & -3.18 \\ \text { 3.Normality } & 12.71 & 5.07 & 9.03 & 4.73 \\ \text { 4.Skewness } & -.30 & -.12 & -.32 & -.06 \\ \text { 5.Kurtosis } & 4.17 & 3.78 & 3.88 & 3.79 \\ \text { 6.Ljung-Box Q (24 autoc.) } & 26.06 & 19.11 & 25.81 & 19.80 \\ \text { 7.Pierce Qs-stat (2 autoc.) } & 1.67 & 1.16 & 2.10 & 3.31 \\ \text { 8.Q-stat for squared residuals. } & 18.3 & 30.3 & 25.2 & 30.7 \\ \text { 9. Run of residuals } & .75 & .75 & .60 & .60\end{array}$

CRITERIA: 1. As small as possible;

2. As small as possible;

3. < 6 (95\% Chi-squared 2 d.f. );

4. $||<.2 \times .184$;

5. $||<.3+2 \times .365$;

6. $||<$.34 (95\% Chi-squared 22 d.f);

7. $\mid$. $<6$ (95\% Chi-squared 2 d.f. );

8. $||<$.34 (95\% Chi-squared 22 d.f. );

9. $||<.2(95 \% \mathrm{t}$-value $)$

Note: |.| denotes absolute value; SE of skewness estimator: .184; SE of kurtosis estimator .365. 


\section{TABLE 3: SUMMARY STATISTICS; SEATS}

\section{MODEL}

10. Component Innovation Variance ( in units of Va )

Trend

Seasonal

Irregular

SA series

\section{$\begin{array}{llll}1^{(*)} & 2 & 3 & 4\end{array}$}

$\begin{array}{llll}.324 & .276 & .200 & .264 \\ .038 & .017 & .016 & .023 \\ .077 & .119 & .165 & .110 \\ .724 & .802 & .797 & .767\end{array}$

11. Estimation Error Variance ( in units of Va)

$\begin{array}{lllll}\text { Trend } & .451 & .320 & .305 & .351\end{array}$

SA series

$\begin{array}{llll}.394 & .228 & .189 & .266\end{array}$

12. SD of revision in concurrent estimator ( in $\%$ points )

$\begin{array}{lllll}\text { Trend } & .089 & .082 & .078 & .080 \\ \text { SA series } & .084 & .071 & .062 & .070\end{array}$

13. Significance of seasonality (95\%): \# significant months per year

Historical Estimation

Preliminary Estimation

Next year forecast

$4 \quad 6 \quad 6 \quad 6$

$2=5 \quad 5 \quad 6$

$\begin{array}{llll}0 & 5 & 4 & 4\end{array}$

14. Convergence ( $\%$ decrease in variance of revision error after five years )

\begin{tabular}{|c|c|c|c|c|}
\hline Trend & 86 & 78 & 82 & 8 \\
\hline SA series & 85 & 72 & 73 & 7 \\
\hline $\begin{array}{l}\text { 15. Gain from concurrent adjustment } \\
\text { ( } \% \text { decrease in RMSE ) }\end{array}$ & 12 & 7 & 7 & \\
\hline $\begin{array}{l}\text { 16. Diagnostics: Comparation of ACF and } \\
\text { CCF }\end{array}$ & OK & OK & OK & \\
\hline
\end{tabular}

CRITERIA: 10. For the trend and seasonal component, as small as possible; for the irregular as large as possible.

11. As small as possible;

12. As small as possible;

13. As many as possible;

14. As large as possible.

(*) The SEATS results are for the approximation to Model 1 


\section{COMMENTS TO TABLES 2 AND 3}

1) $\mathrm{ROW} 2-9$

BIC denotes the Bayesian Information Criterion. The normality, skewness, kurtosis and the Ljung-Box Q-statistics (which tests the hypothesis of no residual autocorrelation ) are described, for example, in Harvey (1993). The Pierce- $Q_{s}$-statistics tests for the lack of seasonal autocorrelation in the residuals, and is described in Pierce (1978). The Q-statistics for the squared residuals is a test for linearity of the process; see, for example, Mills (1990). Finally, the residual-run-statistics tests for randomness in the signs of the residuals.

2) ROWS 10-11

In order to standarize measurements, variances are expressed as a fraction of the variance of the residuals $a_{t}$.

3) $\mathrm{ROW} 10$

The innovations in the components are the cause of their stochastic behavior (i.e, their "moving" features). The larger is the variance, the more volatile the component will be. The trend and seasonal component should be as smooth and stable as possible, and hence the irregular should absorb as much noise as possible.

4) ROW 11

The error includes the sum of the one in the final estimator plus the revision error (see, Maravall, 1995)

5) ROW 12

The revision error variances, from the SEATS output, are multiplied by Va in order to express the SD in the series units (\% points). The revisions are of moderate size, in all cases smaller than one-tenth of a percent point. Confidence intervals, based on revisions, around the concurrent estimators can be immediately obtained. 


\section{6) $\mathrm{ROW} 13$}

The significance of seasonality is determined for the historical and preliminary (last year) estimators and for the one-year-ahead forecasts of the seasonal component. A seasonal component estimate is significant if ( in absolute terms ) its value is $>2 \times$ SE of the estimate. It is seen that, for Model 1 , although historical estimation detects significant seasonality in the series, preliminary and concurrent estimation will be fairly unreliable, and forecasts useless. On the contrary, seasonality is significant for historical and preliminary estimators, and also for forecasts, in the other three models.

\section{7) ROWS 14-15}

Row 14 shows the percentage of the revision error variance that has disappeared after 5 more years of data have become available. Row 15 shows how much is gained if concurrent (instead of once-a-year) adjustment is performed. Convergence is seen to be in all cases slow. Accordingly, the improvement in MSE that can be achieved by moving from a once-a-year adjustment to a concurrent one is also small in all cases.

\section{8) $\mathrm{ROW} 16$}

The SEATS diagnostics are those associated with the comparison of the ACF and the crosscorrelation function (CCF) of the stationary transformation of the components, their theoretical estimators, and their empirical estimates. The variance of the theoretical component should be larger than those of the theorical estimator and estimate actually obtained; theoretical estimators and empirical ones should be close (see Maravall, 1987). These requirements, as indicated in the output of SEATS, are satisfied in all four cases. 


\section{The Decomposition in Figures}

Figure 1: ORIGINAL AND LINEARIZED SERIES
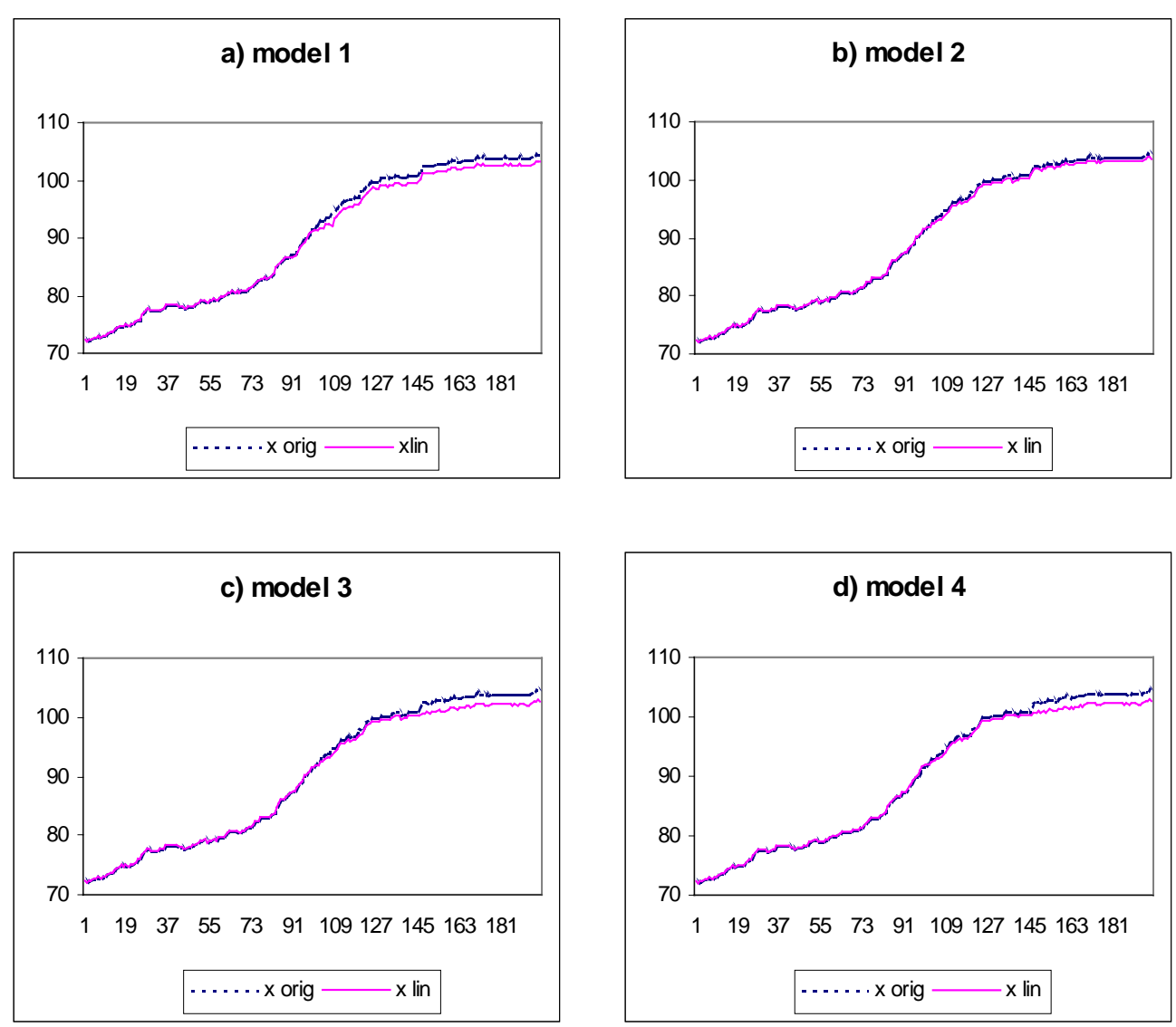
Figure 2: RESIDUALS
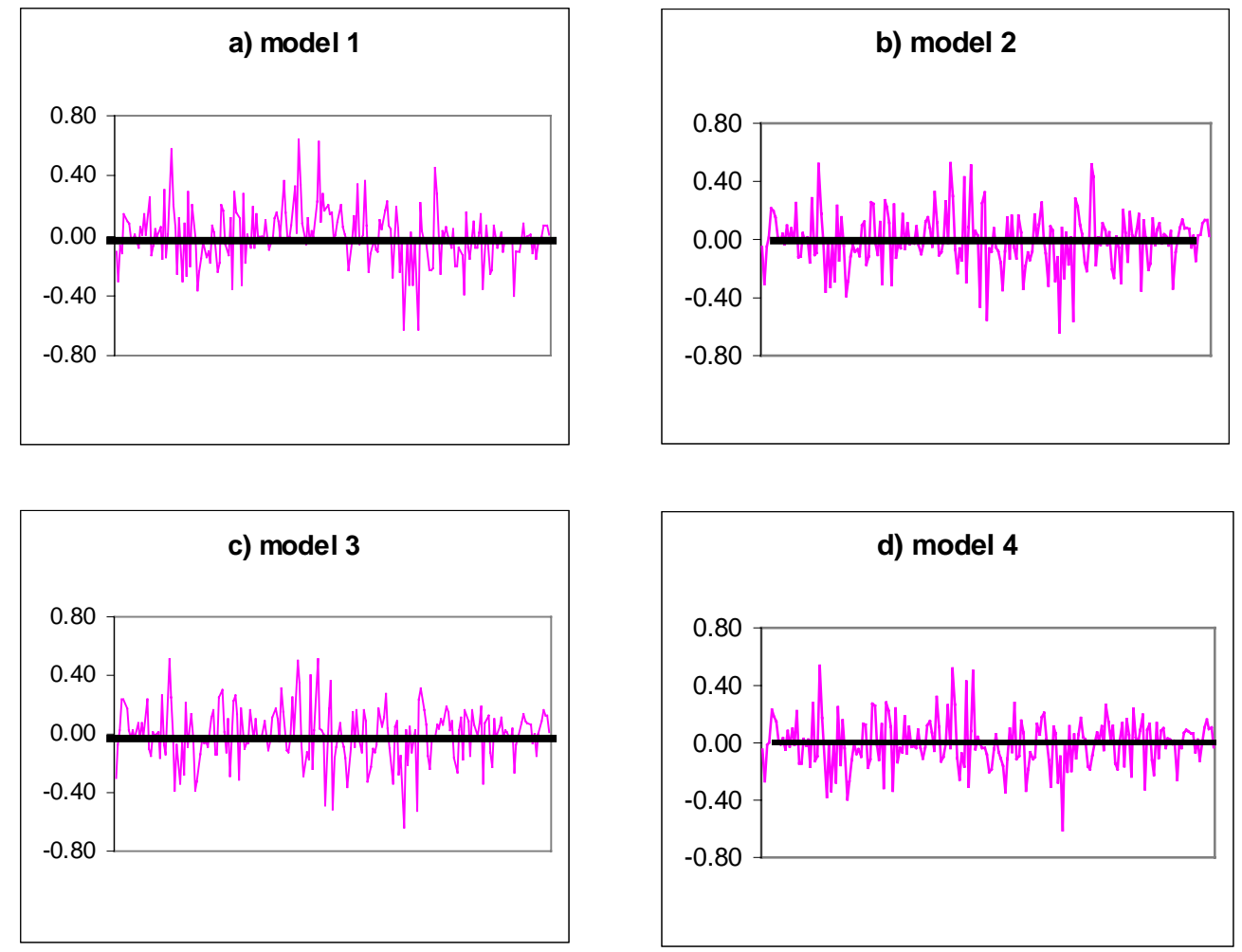
Figure 3: ACF OF RESIDUALS
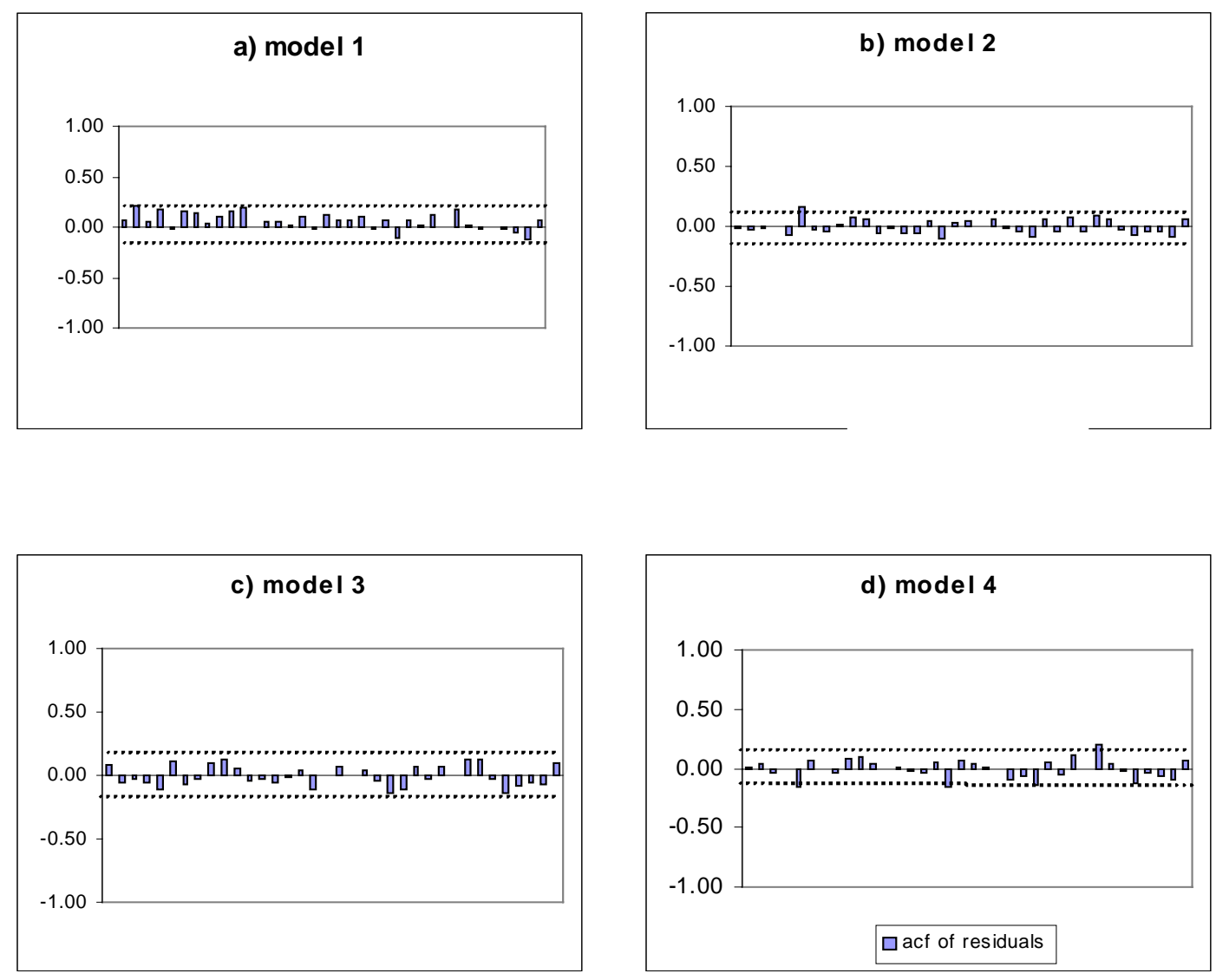

BANCO DE ESPAÑA / DOCUMENTO DE TRABAJO 0014 
Figure 4: RATES OF GROWTH: TREND AND ORIGINAL
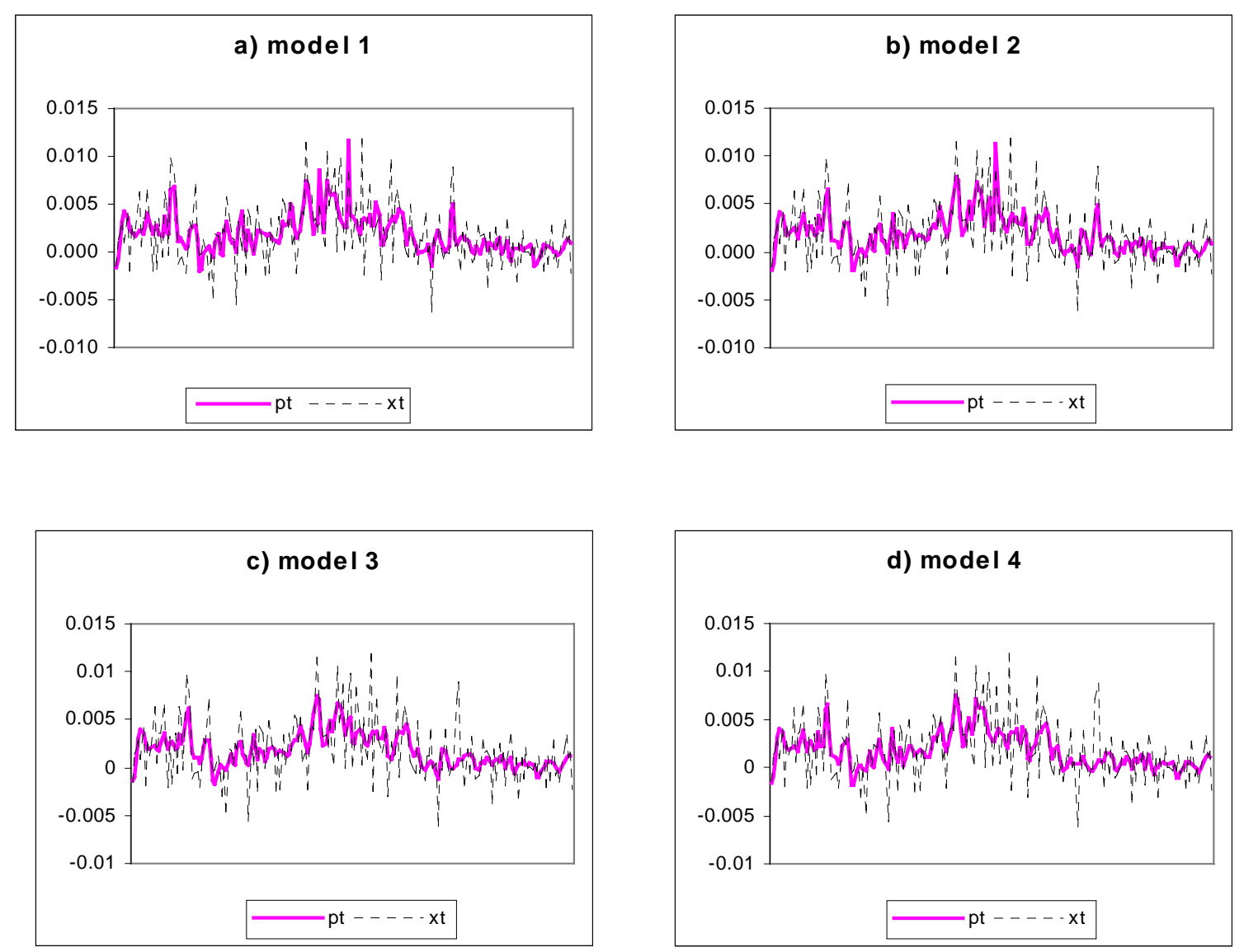
Figure 5: SEASONAL COMPONENT
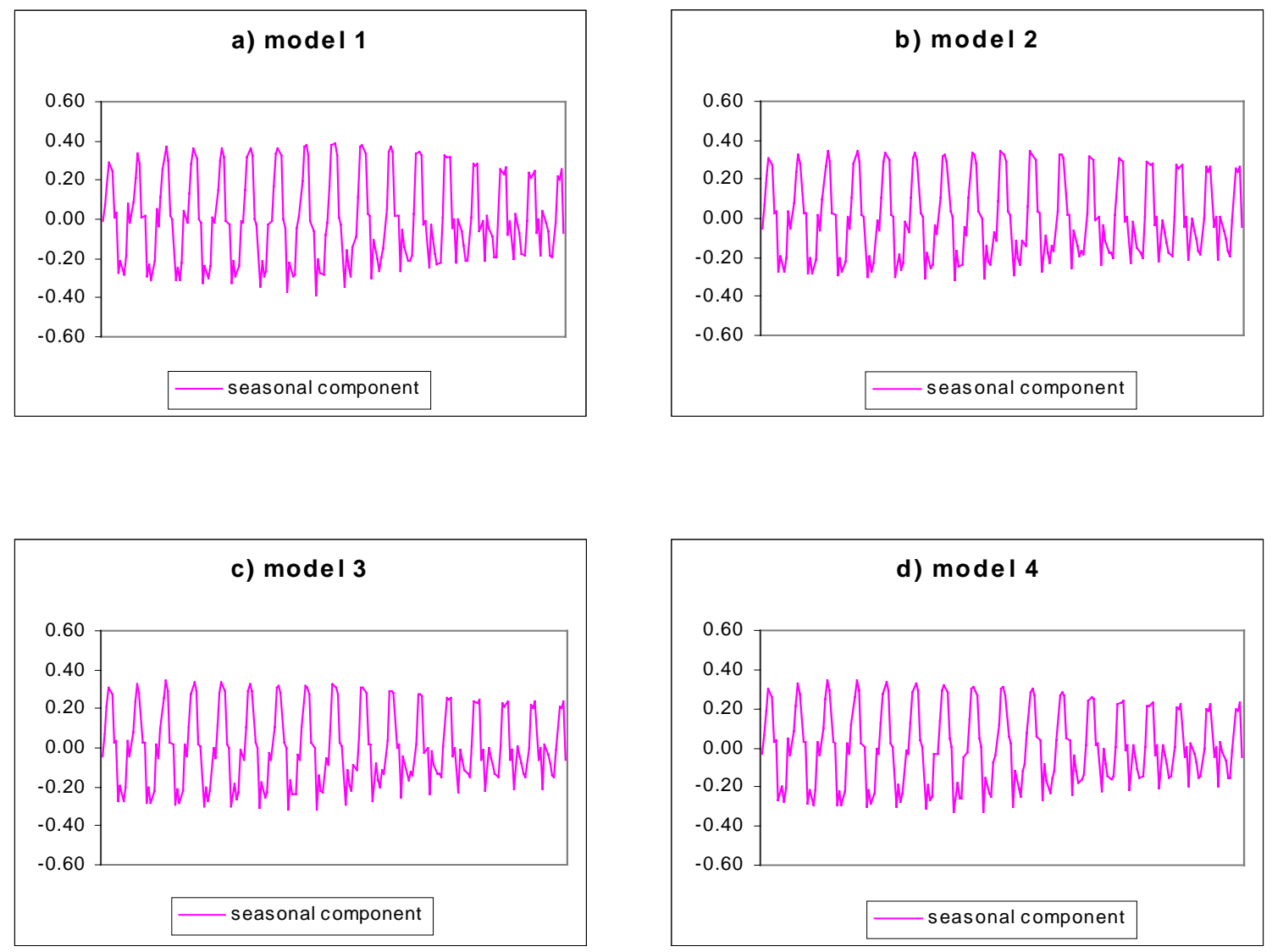

BANCO DE ESPAÑA / DOCUMENTO DE TRABAJO 0014 
Figure 6: IRREGULAR COMPONENT
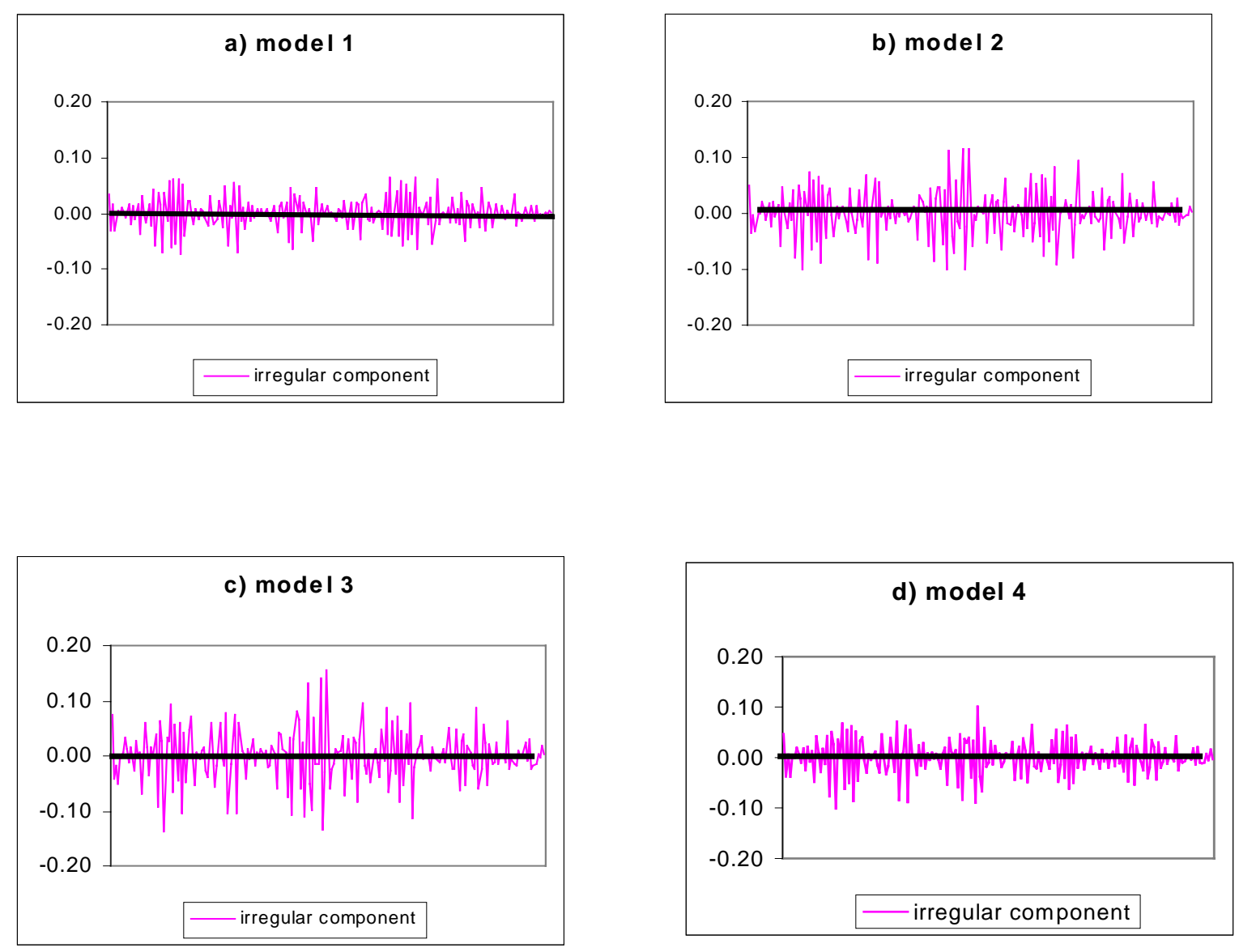
Figure 7: SPECTRA ON THE COMPONENTS
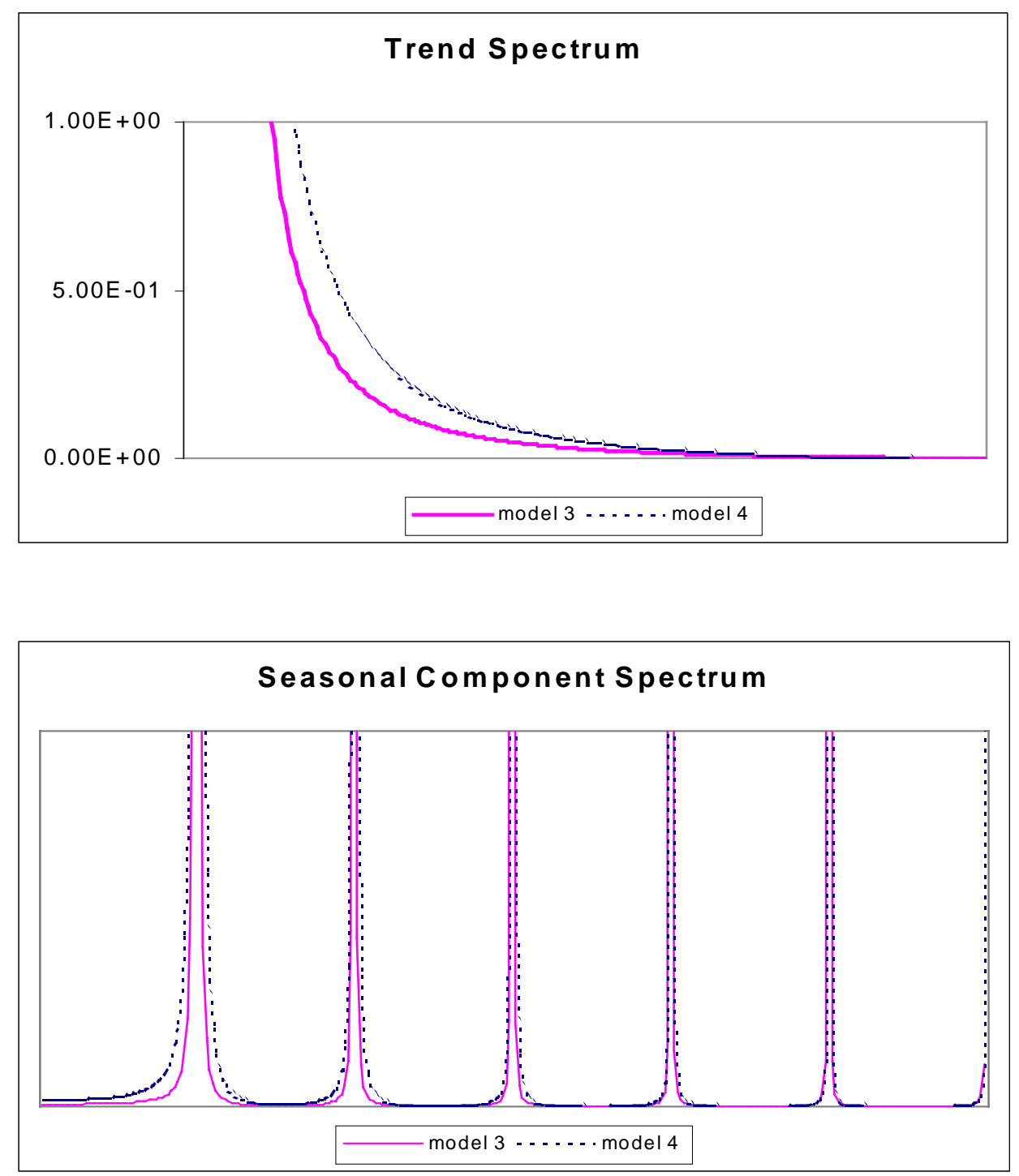

BANCO DE ESPAÑA / DOCUMENTO DE TRABAJO 0014 
Figure 8: SQUARED GAIN OF FILTERS
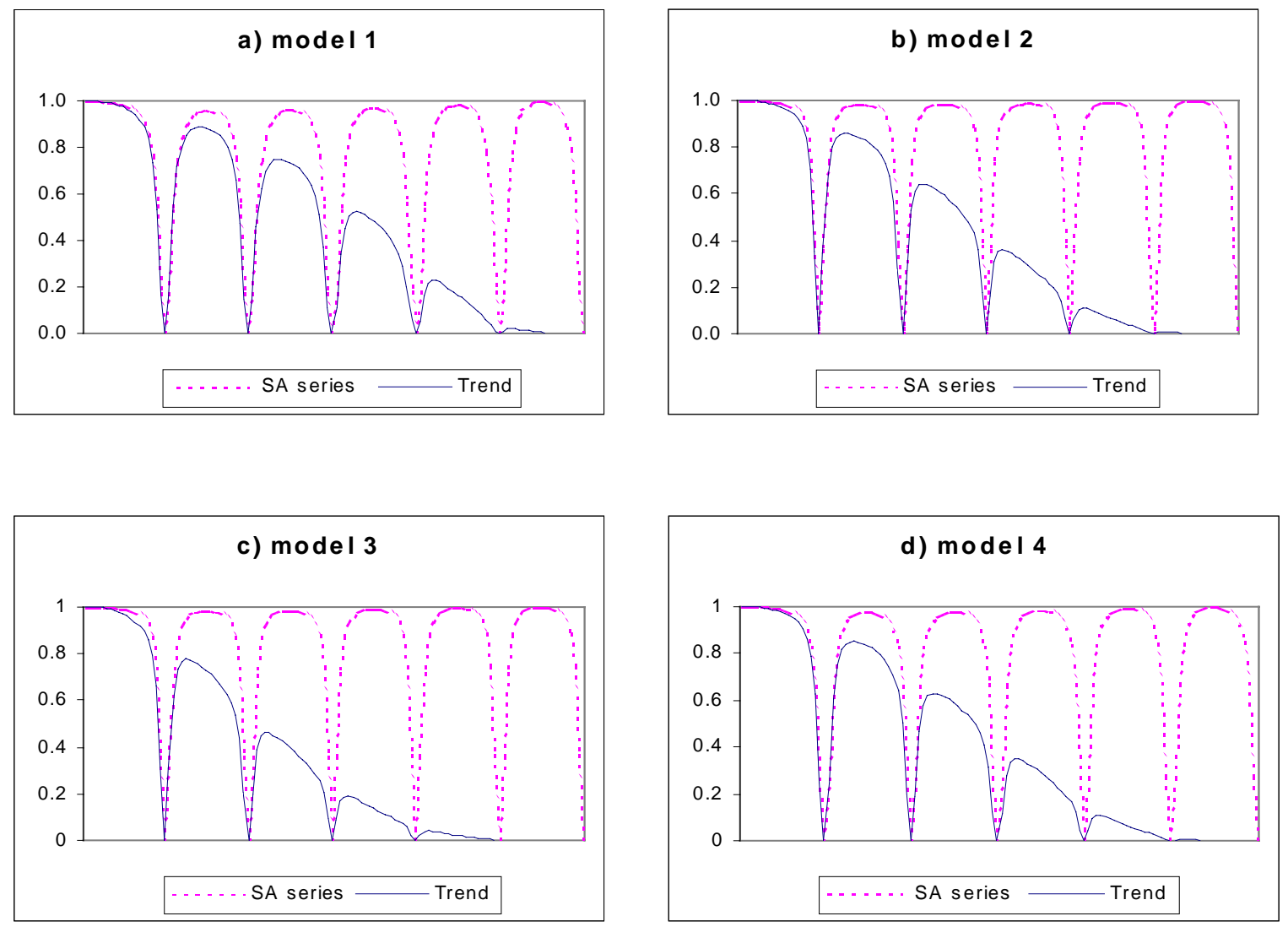

BANCO DE ESPAÑA / DOCUMENTO DE TRABAJO 0014 
Figure 9: WIENER-KOLMOGOROV FILTERS
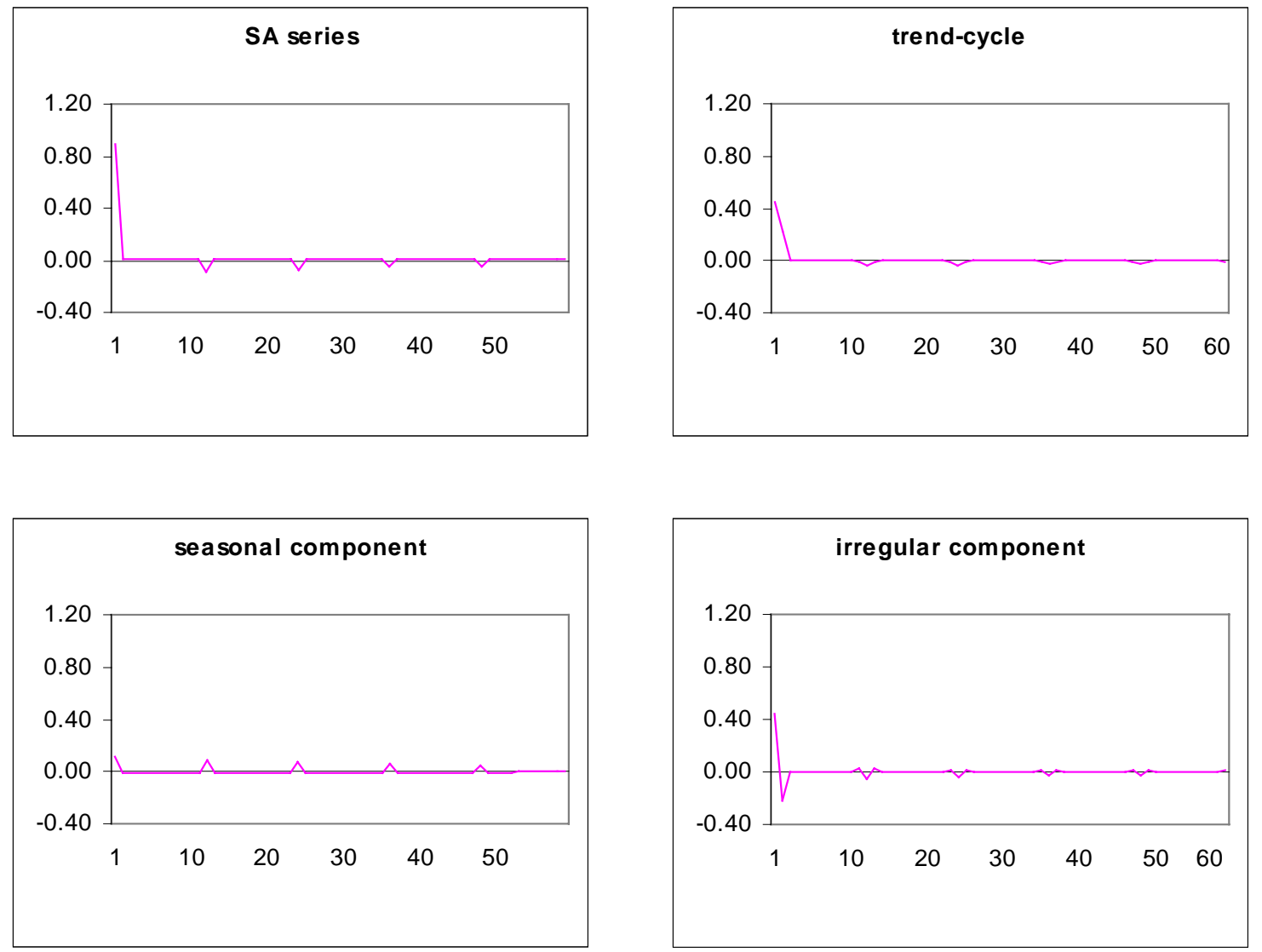

BANCO DE ESPAÑA / DOCUMENTO DE TRABAJO 0014 
Figure 10: CHOSEN DECOMPOSITION
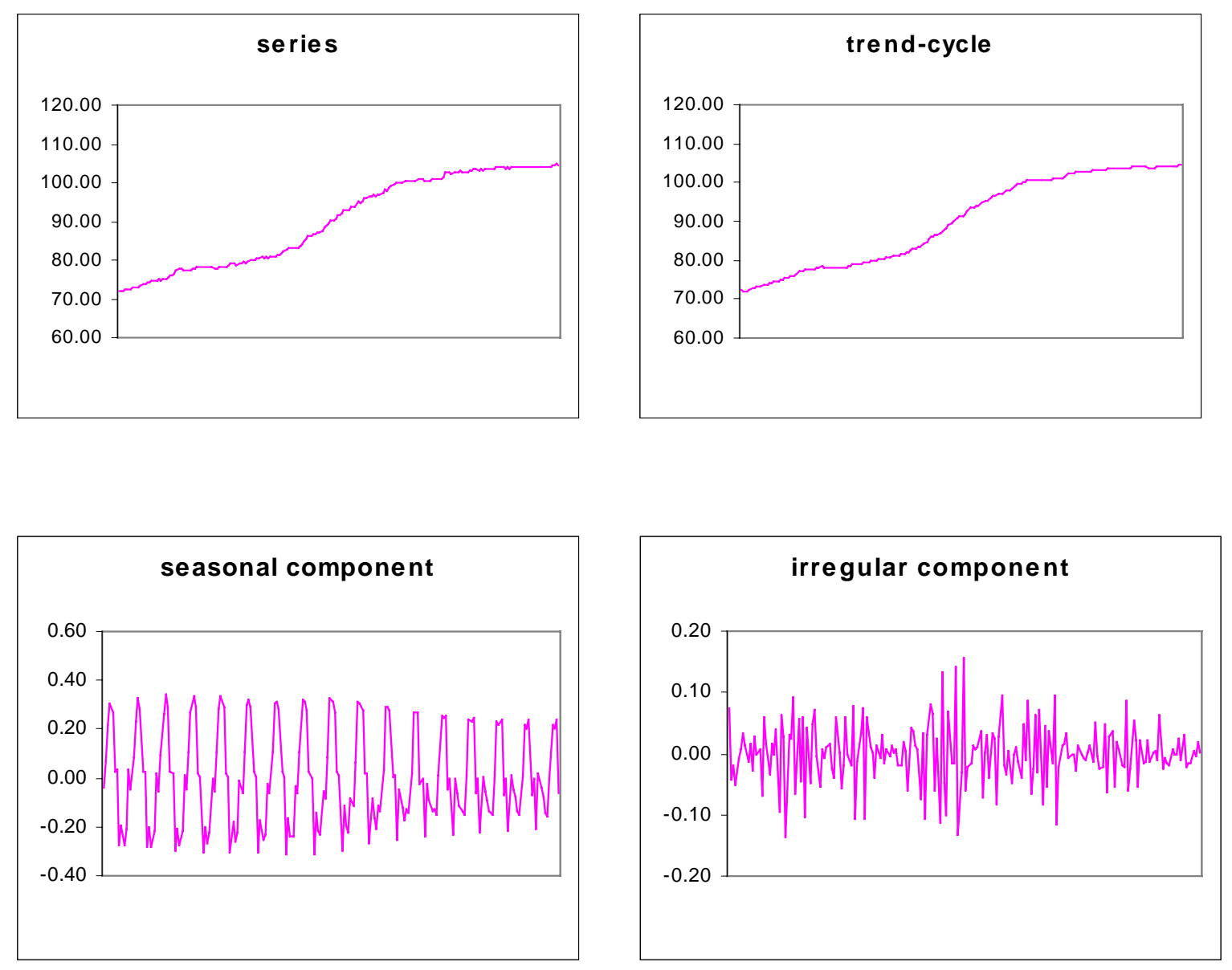

BANCO DE ESPAÑA / DOCUMENTO DE TRABAJO 0014 
Figure 11: FORECAST
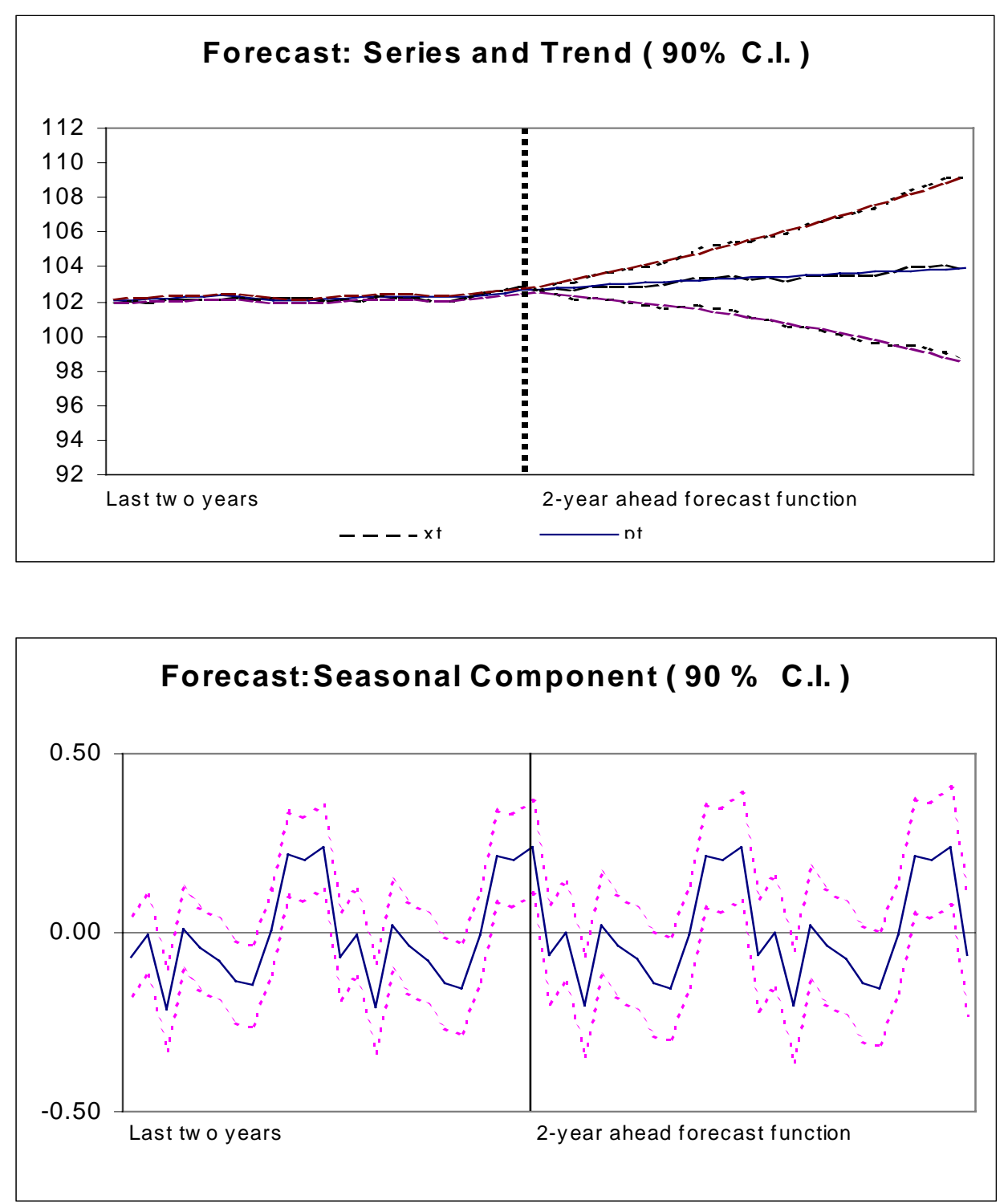


\section{Out-of-sample month-to month performance}

The previous exercise was made following a consultation from Nicolas Fasel (Swiss Statistical Office) and, at that time, the series ended in May 1999. Since then, 10 more observations have become available, and we shall use them to test out-of-sample performance of the procedure. As explained in Gómez and Maravall (1998), month-to-month routine application of TRAMO-SEATS should consist of, once an initial identification of the model has been selected, to mantain it for a year unless some drastic error becomes apparent, after which a new reidentification should be made. The procedure implies fixing for the next 12 months: the orders $(p, d, q)(P, D, Q)_{12}$, as well as the log/level and mean/no-mean choices, the type and location of outliers already identified, and regression variables included in the original identification, while maintaining during the year the automatic outlier detection. Then, every month one reestimates simply the values of the parameters. For the chosen model ( Model 3) this means that, for the 10 extra months, the model " $(0,2,1)(0,1,1)_{12}$ in the levels and no mean ", the LS outlier for 5/91, and the AOs for 11/91 and 11/92, are maintained, as well as the VAT-effect regression variable ( with 2 months to reach the level ). Figure 12 compares the monthly forecast with the observations, and displays the forecast errors. The mean of the error is 0.023 , and the SD is equal to 0.157 . The zero mean hypothesis can be accepted, and the variance is not significantly different from the in-sample value; it is, in fact, a bit smaller. The forecast errors show no evidence of misspecification. Moreover, when the model is reidentified for the extended sample, the results barely change, as shown in Table 4. No new outliers are detected, and the only difference worth pointing out is a slight decrease in the significance of seasonality for historical estimation, associated with the slight increase in seasonal volatility.

In fact, if reidentification starts, as is usually the case, with the fully automatic procedure ( with the VAT effect included ) the model obtained is a $(1,1,1)(0,1,1)_{12}$ model, with the regular AR polynomial equal to (1-.96B). Given that it is reasonable to replace this root by $(1-B)$, the model reidentified after the new 10 months of observations is the same as Model 3 with very similar parameters estimates. The behaviour of TRAMO-SEATS has been, as a consequence, stable over the out-of-sample period. 


\section{TABLE 4: REIDENTIFICATION OF MODEL}

\section{TRAMO}

$\begin{array}{ll}\text { Model identified: } & \text { Model } 3 \\ \theta_{1}: & -.833 \\ \theta_{12}: & -.749 \\ \text { Outliers: } & \text { Same as Model } 3 \\ \text { SE ( residuals ) } & .193 \\ \text { BIC: } & -3.14 \\ \text { BL-Q-stat: } & 25.0 \\ \text { Kurtosis } & 3.81\end{array}$

\section{SEATS}

Variance ( innovation trend ): $\quad .195$

Variance ( innovation seasonal ): $\quad .019$

Variance ( innovation irregular): $\quad .161$

SD ( revision in conc. estimator trend ): $\quad .077$

SD ( revision in conc.estim. SA series): $\quad .062$

Significance of seasonality, Historical $\quad 5 / 12$

Significance of seasonality, Preliminary: $4 / 12$

Significance of seasonality; Forecast; $\quad 4 / 12$

\section{Conclusion}

The paper applies TRAMO-SEATS to the CPI monthly swiss series, and illustrates how the programs output can be used to discriminate among alternative models and decompositions. In particular, it is seen how the SEATS output can be used to choose a model for seasonal adjustment, among the ones that are equally compatible with the sample. The identification and estimation of the model is done for data finishing in May 1999, and 10 months of additional observations are used to illustrate the out-of-sample performance. The model selected ( the result of the automatic procedure, with a regression variable capturing a VAT increase ) is seen to perform very well, and remains unchanged when reidentification is made after incorporation of the out-of-sample values. 
Figure 12: OUT-OF-SAMPLE PERFORMANCE
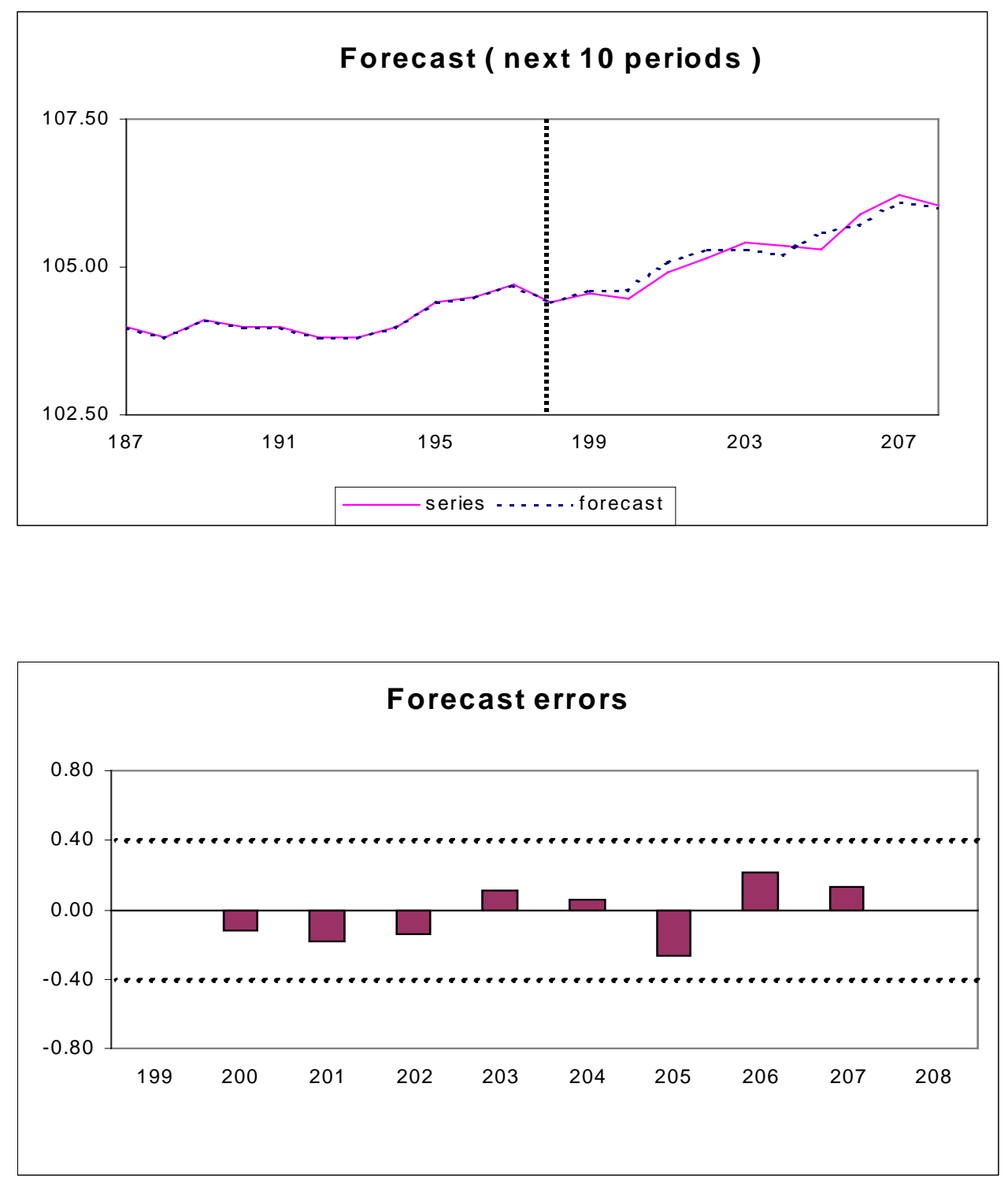


\section{References}

Bell, W.R. and Hillmer, S.C. (1984), " Issues Involved with the Seasonal Adjustment of Economic Time Series " Journal of Business and Economic Statistics 2, 291-320.

Burman, J.P. (1980). Seasonal Adjustment by Signal Extraction. Journal of Royal Statistical Society A, 143, 321-337.

Cleveland, W.P. and Tiao, G.C. (1976) " Decomposition of Seasonal Time Series: a Model for the X11 Program", Journal of the American Statistical Association 71, 581-587.

Findley, D.F., Monsell, B.C., Bell, W.R., Otto, M.C. and Chen, B.C. (1998), " New Capabilities and Methods of the X12 ARIMA Seasonal Adjustment Program " (with discussion), Journal of Business and Economic Statistics, 16, 127-177.

Harvey, A.C. (1993). Time Series Models. Deddington: Philip Allan.

Hillmer, S.C. \& Tiao, G..C. (1982). An Arima-Model Based Approach to Seasonal Adjustment. Journal of the American Statistical Association 77,63-70.

Gómez,V. \& Maravall, A. (2000a). Automatic Modelling Methods for Univariate Series. Working Paper 9808, Research Department, Bank of Spain. To appear as Ch.7 in Peña, D., Tiao, G.C. \& Tsay, R.S (eds.) A Course in Advanced Time Series Analysis, New York: J.Wiley \& Sons.

Gómez,V. \& Maravall,A. (2000b). Seasonal Adjustment and Signal Extraction in Economic Time Series. Working Paper 9808, Research Department, Bank of Spain. To appear as Ch.8 in Peña, D., Tiao, G.C. \& Tsay, R.S. (eds.) A Course in Advanced Time Series Analysis, New York: J.Wiley \& Sons.

Gómez, V. \& Maravall, A. (1998). Guide for Using the Programs TRAMO and SEATS. Working Paper 9805, Research Department, Bank of Spain.

Gómez, V. \& Maravall, A. (1996). Programs TRAMO (Time Series Regression with Arima noise, Missing observations, and Outliers) and SEATS (Signal Extraction in Arima Time Series). Instruction for the User. Working Paper 9628 ( with updates ), Research Department, Bank of Spain.

Gómez, V. \& Maravall, A. (1994). Estimation, Prediction and Interpolation for Nonstationary Series with the Kalman Filter, Journal of the American Statistical Association 89, 611-624.

Maravall, A. (1995). Unobserved Components in Economic Time Series, in Pesaran, H. \& Wickens, M. (eds), The Handbook of Applied Econometrics, vol. 1, Oxford: Basil Blackwell.

Maravall, A. (1987), "On Minimum Mean Squared Error Estimation of the Noise in Unobserved Component Component Models", Journal of Business and Economic Statistics 5, 115-120.

Maravall, A. and Pierce, D.A. (1987), "A Prototypical Seasonal Adjustment Model", Journal of Time Series Analysis 8, 177-193. Reprinted in Hylleberg, S. (ed.), Modelling Seasonality, Oxford University Press, 1992. 
Mills, T.C. (1990). Time Series Techniques for Economist, Cambridge: Cambridge University Press.

Pierce, D.A. (1978), "Seasonal Adjustment when Both Deterministic and Stochastic Seasonality are Present", in Zellner, A. (ed.), Seasonal Analysis of Economic Time Series, Washington, D.C.: U.S. Dept. of Commerce Bureau of the Census, 242-269. 